\title{
ELECTROCATALYTIC ACTIVITY OF CHEMISORBED HYDROXYL ION TOWARDS OXIDATION OF HYDROGEN PEROXIDE ANION IN ALKALINE MEDIA
}

\author{
MD. REZWAN MIAH*, TARANNUMA FERDOUS MANNY, DEBASHIS SEN, \\ MD. AZIZUR RAHMAN ${ }^{1}$, MD. SAIFUL ALAM, RAMKRISHNA SAHA, \\ MD. TOWHIDUL ISLAM TAREQE AND MD. RAKIB MAHMUD
}

Department of Chemistry, School of Physical Sciences, Shahjalal University of Science and Technology, Sylhet-3114, Bangladesh

\begin{abstract}
In situ chemisorbed hydroxyl ion $\left(\mathrm{OH}^{-}\right)$onto clean polycrystalline gold ( $\mathrm{Au}$ (poly)) electrode showed an extraordinary enhanced electrocatalytic activity towards oxidation of hydrogen peroxide anion $\left(\mathrm{HO}_{2}{ }^{-}\right)$in alkaline media. The oxidation of $\mathrm{HO}_{2}{ }^{-}$at the fabricated electrode was found to be a diffusion controlled process. The anodic transfer coefficient of the oxidation reaction was estimated as 0.47. Chloride ion $\left(\mathrm{Cl}^{-}\right)$replaced the chemisorbed $\mathrm{OH}^{-}$from the surface of the modified $\mathrm{Au}$ (poly) $\left(\mathrm{OH}^{-} \mid \mathrm{Au}\right.$ (poly)) electrode leading to diminishing the observed electrocatalytic activity. The optimized concentration of $\mathrm{KOH}$ solution for the highest catalytic activity was found to be ca. 0.1 M. A linear calibration curve for various concentrations of $\mathrm{HO}_{2}^{-}$in the range of 0.5 to $5 \mathrm{mM}$ was obtained having sensitivity equal to $1.028 \mathrm{~A} \mathrm{~cm}^{-2} \mathrm{M}^{-1}$.
\end{abstract}

Key words: Chemisorption of $\mathrm{OH}^{-}$, Surface coverage, Hydrogen peroxide oxidation, Electrocatalysis, Competitive adsorption, Calibration curve

\section{INTRODUCTION}

$\mathrm{HO}_{2}^{-}$is one of the most consumed chemicals in various sectors such as food, clinical, pharmaceutical, industrial and environmental analysis etc. Detection of its proper level of concentration is very important and hence has received considerable scientific interests since long. Electrochemical sensing is one of the promising techniques towards the detection of $\mathrm{HO}_{2}^{-}$. $\mathrm{HO}_{2}^{-}$can be detected by both of its electrochemical oxidation and reduction but the latter has received less attention. This is because of lack of suitable electrode materials as they undergo oxidative degradation by $\mathrm{HO}_{2}{ }^{-}$and positive applied potential. Different electrode materials have been utilized for oxidation of $\mathrm{HO}_{2}^{-}$. For examples, platinized (Pt-black) electrode (V. Badets et al. 2016), Pt (E. Nouri-Nigjeh et al. 2012), gold nano-particles (C.-H. Lin et al. 2015), film of microspheres $\mathrm{MnO}_{2}$ and Nafion composite fabricated on glassy carbon electrode and flower like copper oxide (L. Zhang et al. 2009, 2011) etc. have been used.

* Corresponding author: <rezwan-che@ sust.edu>.

${ }^{1}$ Department of Chemistry, Mississippi State University, MS 39759, USA. 
We have been increasingly interested to develop stable electrode materials, particularly by modification of soft metallic electrodes such as Ag and Au etc. with spontaneously chemisorbed anionic species, for electrochemical oxidation of $\mathrm{HO}_{2}^{-}$. For examples, we reported that the $\mathrm{Au}$ (poly) electrode modified with sub-monolayer of iodine and bromine (Miah et al. 2006, 2009) formed by the spontaneous chemisorption of iodide and bromide possessed an excellent enhanced stable electrocatalytic activity towards oxidation of $\mathrm{HO}_{2}^{-}$. Very recently we reported that $\mathrm{OH}^{-} \mid \mathrm{Au}$ (poly) electrode in situ fabricated by the chemisorption of $\mathrm{OH}^{-}$also shows a significant catalytic effect towards the oxidation of $\mathrm{HO}_{2}^{-}$(Miah et al. 2016) in alkaline media. The peak current of $\mathrm{HO}_{2}^{-}$oxidation was significantly enhanced as compared with the plateau current achieved at the bare $\mathrm{Au}$ (poly) electrode under the same experimental conditions. A mechanism of the observed enhanced catalytic activity was discussed based on the electrostatic attraction of the $\mathrm{OH}^{-}$induced positively charged $\mathrm{Au}$ (poly) electrode surface and negatively charged $\mathrm{HO}_{2}^{-}$.

In the present article, we have demonstrated the catalytic activity of the in situ fabricated $\mathrm{OH}^{-} \mid \mathrm{Au}$ (poly) electrode towards oxidation of $\mathrm{HO}_{2}^{-}$. The stability of the catalytic activity has been investigated. Poisoning of catalytic activity of $\mathrm{OH}^{-} \mid \mathrm{Au}$ (poly) electrode by chloride $\left(\mathrm{Cl}^{-}\right)$, effect of $\mathrm{pH}$ of the electrolytic solution and electrode holding time in solution etc. have been described. A calibration curve for detection of $\mathrm{HO}_{2}^{-}$has also been achieved.

\section{EXPERIMENTAL}

The working ( $\mathrm{Au}$ (poly)), counter (Pt spiral wire), and reference ( $\mathrm{Ag} / \mathrm{ACl} / \mathrm{NaCl}$ (sat.)) electrodes, electrochemical cell (two-compartment Pyrex glass), polishing and pretreatment techniques were as same as those described earlier (Miah et al. 2016). The polycrystalline nature of the $\mathrm{Au}$ (poly) electrode was identified by recording the characteristic cyclic voltammogram as reported elsewhere (Miah et al. 2016). The electrolytic solution was purged with $\mathrm{N}_{2}$ gas for $10 \mathrm{~min}$. During the measurements, $\mathrm{N}_{2}$ gas was flashed over the cell solution to maintain $\mathrm{N}_{2}$ saturation for avoiding interference of $\mathrm{O}_{2}$. The necessary amount of $\mathrm{HO}_{2}{ }^{-}$was added into the solution whenever needed. The measurements were performed at temperature of $25 \pm 1^{\circ} \mathrm{C}$. The $\mathrm{OH}^{-} \mid \mathrm{Au}$ (poly) electrodes were fabricated by stirring the $\mathrm{KOH}$ solution for $5 \mathrm{~min}$ if otherwise not mentioned. Necessary amount of $\mathrm{Cl}^{-}$was added into the electrolytic solution to investigate its poisoning effect on the catalytic activity of the $\mathrm{OH}^{-} \mid \mathrm{Au}$ (poly) electrodes. Effect of $\mathrm{pH}$ was investigated using $\mathrm{KOH}$ solution having its concentration in the range of $0.00625-1.0$ M. The scan rate of the electrochemical measurements was $0.1 \mathrm{~V} \mathrm{~s}^{-1}$ if otherwise not mentioned. Electrochemical measurements were performed using a CHI 602D electrochemical analyzer. 


\section{RESULTS AND DISCUSSION}

Effect of scan rate on the oxidation of $\mathrm{HO}_{2}{ }^{-}$at the $\mathrm{OH}^{-} \mid \mathrm{Au}$ (poly) electrode: It has been described in our recent article (Miah et al. 2016) that oxidation peak current of $\mathrm{HO}_{2}^{-}$at the $\mathrm{OH}^{-} \mid \mathrm{Au}$ (poly) electrode is significantly higher as compared with that obtained at the bare $\mathrm{Au}$ (poly) electrode the same experimental conditions. The oxidation of $\mathrm{HO}_{2}{ }^{-}$at the $\mathrm{OH}^{-} \mid \mathrm{Au}$ (poly) electrode was investigated over a wide potential scan rates and the corresponding LSVs are presented in Fig. 1. It clearly shows that the responses are very stable all over the potential scan rates. The anodic peak currents for the catalytic oxidation of $\mathrm{HO}_{2}{ }^{-}$were derived from the obtained LSVs and the values were plotted against the square root of scan rates and the result is shown in Fig. 2 (a). The values nicely fall on a straight line passing through the origin suggesting that the oxidation of $\mathrm{HO}_{2}{ }^{-}$at the $\mathrm{OH}^{-} \mid \mathrm{Au}$ (poly) electrode is a diffusion controlled process (Miah et al. 2006, 2009).

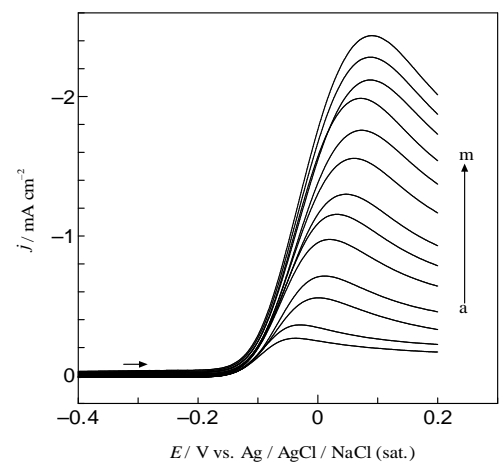

Fig. 1. LSVs obtained the $\mathrm{OH}^{-} \mid \mathrm{Au}$ (poly) electrode in $0.1 \mathrm{M} \mathrm{KOH}$ solution containing 1.0 $\mathrm{mM} \mathrm{HO}_{2}^{-}$at various scan rates of (a) 0.005 , (b) 0.01 , (c) 0.03 , (d) 0.05 , (e) 0.10 , (f) 0.15 , (g) 0.20, (h) 0.30, (i) 0.40, (j) 0.50, (k) 0.60, (l) 0.70, (m) $0.80 \mathrm{~V} \mathrm{~s}^{-1}$ (form bottom to top).

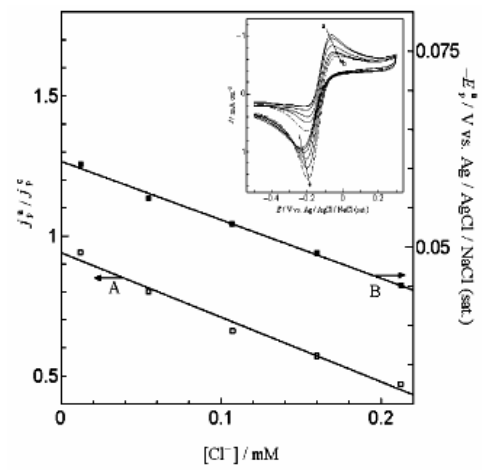

Fig. 2. Linear plots of (a) $-J_{\mathrm{p}}$ vs. $v^{1 / 2}$ and (b) $E_{\mathrm{p}}$ vs. $\log v$ for the oxidation of $\mathrm{HO}_{2}{ }^{-}$. The data were derived from LSVs in Fig. 1. 
The peak potentials were also derived and plotted against $\log \left(v / \mathrm{V} \mathrm{s}^{-1}\right)$ and the result is presented in Fig. 2 (b). The slope of the straight line was obtained as $0.0631 \mathrm{~V}^{\text {decade }}{ }^{-1}$ from which the anodic transfer coefficient of oxidation $\mathrm{HO}_{2}^{-}$was calculated as 0.47 (Laviron 1979) considering two electron oxidation of $\mathrm{HO}_{2}^{-}$.

Competitive adsorption of $\mathrm{Cl}^{-}$: $\mathrm{Cl}^{-}$undergoes more efficient adsorption at the $\mathrm{Au}$ (poly) electrode surface (Marichev 1998) than $\mathrm{OH}^{-}$and hence it can replace the adsorbed $\mathrm{OH}^{-}$. Therefore, oxidation of $\mathrm{HO}_{2}^{-}$was performed in the presence of $\mathrm{Cl}^{-}$to further explore the catalytic activity of the chemisorbed $\mathrm{OH}^{-}$. CVs were accordingly obtained at the $\mathrm{OH}^{-} \mid \mathrm{Au}$ (poly) electrode in $0.1 \mathrm{M} \mathrm{KOH}$ solution containing $1.0 \mathrm{mM} \mathrm{HO}_{2}^{-}$in the presence of (a) 0.0125 , (b) 0.055 , (c) 0.1075 , (d) 0.160 and (e) $0.2125 \mathrm{mM} \mathrm{Cl}^{-}$and the results are shown in the inset of Fig. 3. The results show that the oxidation peak current of $\mathrm{HO}_{2}{ }^{-}$significantly decreased in the presence of $\mathrm{Cl}^{-}$. The decrease of the anodic peak current is attributed to the efficient adsorption of $\mathrm{Cl}^{-}$at the $\mathrm{OH}^{-} \mid \mathrm{Au}$ (poly) electrode surface by replacing $\mathrm{OH}^{-}$.

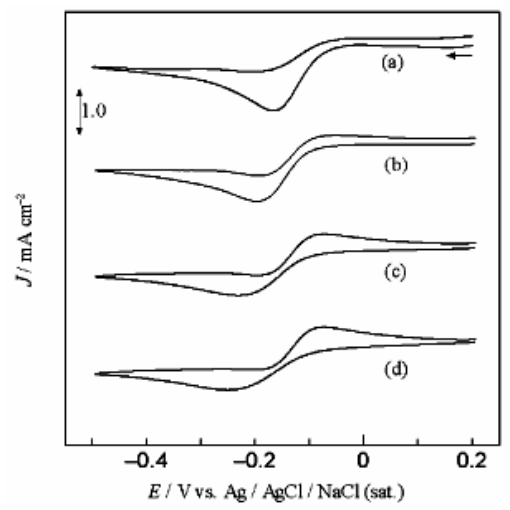

Fig. 3. Linear plots of (A) ratio of anodic to cathodic peak current $\left(j_{p}^{a} / j_{p}^{c}\right)$ vs. concentration of $\mathrm{Cl}^{-}$and (B) anodic peak potential $\left(E_{p}^{a}\right)$ vs. concentration of $\mathrm{Cl}^{-}$. Inset shows the $\mathrm{CVs}$ obtained at the $\mathrm{OH}^{-} \mid \mathrm{Au}$ (poly) electrode in $0.1 \mathrm{M} \mathrm{KOH}$ solution containing $1.0 \mathrm{mM} \mathrm{HO}_{2}^{-}$in the presence of (a) 0.0125 , (b) 0.055 , (c) 0.1075 , (d) 0.160 and (e) $0.2125 \mathrm{mM} \mathrm{Cl}^{-}$.

The ratio of anodic to cathodic peak current was obtained (from the CVs shown in the inset of Fig. 3) and plotted against the concentration of $\mathrm{Cl}^{-}$and the corresponding result is presented in Fig. 3(A). It shows a linear decrease of the values of the ratio suggesting the decrease of the catalytic activity due to the adsorption of $\mathrm{Cl}^{-}$. $\mathrm{Cl}^{-}$also has a significant effects on the oxidation peak potential. Fig. 3(B) shows that the oxidation peak potential shifts quickly to the direction of more positive potential with increasing $\left[\mathrm{Cl}^{-}\right] . \mathrm{F}^{-}$has very low affinity of chemisorption on metal surface compared to $\mathrm{Cl}^{-}$. 
Oxidation of $\mathrm{HO}_{2}^{-}$at the $\mathrm{OH}^{-} \mid \mathrm{Au}$ (poly) electrode in presence of $0.2125 \mathrm{mM}$ of $\mathrm{F}^{-}$ (maximum concentration used for $\mathrm{Cl}^{-}$) was performed (data not shown). The oxidation peak current was found to remain almost unaltered in the $\mathrm{F}^{-}$containing solution, while in $\mathrm{Cl}^{-}$containing solution, the peak current decreased by ca. $50 \%$. Adsorption of $\mathrm{Cl}^{-}$ decreased the value of $\Gamma_{\mathrm{OH}^{-}}{ }^{-}$and consequently resulted in a decrease of the catalytic activity of the electrode towards $\mathrm{HO}_{2}{ }^{-}$oxidation. Deactivation of the electrode material towards oxidation of $\mathrm{HO}_{2}^{-}$by the adsorption of $\mathrm{Cl}^{-}$, sulphate, nitrate, acetate was also described elsewhere (Lin et al. 2015).

Effect of electrode holding time: $\mathrm{CVs}$ in $\mathrm{N}_{2}$-saturated 1.0 M KOH solution containing $1.0 \mathrm{mM} \mathrm{HO}_{2}^{-}$were recorded after holding the clean $\mathrm{Au}$ (poly) electrode in the unstirred solution for different times of (a) 0, (b) 35, (c) 85 and (d) $110 \mathrm{~min}$ and the results are shown in Fig. 4.

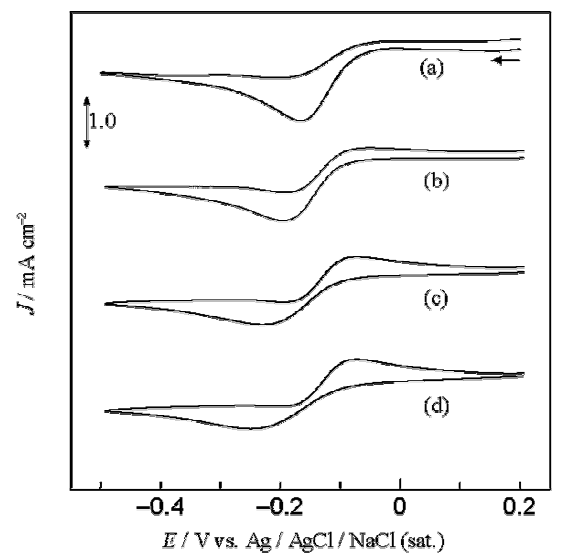

Fig. 4. CVs obtained at the initially clean Au (poly) electrode in $1.0 \mathrm{M} \mathrm{KOH}$ solutions containing $1.0 \mathrm{mM} \mathrm{HO}_{2}{ }^{-}$after holding the electrode in the unstirred solutions for (a) 0, (b) 35, (c) 85 and (d) 110 min.

The results show that the oxidation peak develops while the reduction peak diminishes with time. This is attributed to the gradual chemisorption of $\mathrm{OH}^{-}$and increase of $\Gamma_{\mathrm{OH}}^{-}$, suggesting that the chemisorbed $\mathrm{OH}^{-}$plays a vital role towards the observed catalytic activity for the oxidation of $\mathrm{HO}_{2}^{-}$.

Effects of $\mathrm{KOH}$ concentration on the $\mathrm{HO}_{2}{ }^{-}$oxidation: $\mathrm{CV}$ s were obtained at the $\mathrm{OH}^{-} \mid \mathrm{Au}$ (poly) electrode in $\mathrm{N}_{2}$-saturated $\mathrm{KOH}$ solution having its concentrations in the range of 0.00625 to $1.0 \mathrm{M}$ containing $1.0 \mathrm{mM} \mathrm{HO}_{2}^{-}$. The values of anodic peak current were derived from the CVs and plotted against $[\mathrm{KOH}]$ and the result is shown in Fig. 5 (a). It shows that the anodic peak current passes through a maximum. Increase of [KOH] increases the value of $\Gamma_{\mathrm{OH}}{ }^{-}$at the $\mathrm{OH}^{-} \mid \mathrm{Au}$ (poly) electrode surface. The optimum concentration of $\mathrm{KOH}$ for the highest catalytic activity for the oxidation of $\mathrm{HO}_{2}^{-}$was 
found to be ca. $0.1 \mathrm{M}$. The oxidation peak current above $0.1 \mathrm{M}$ of $\mathrm{KOH}$ decreased probably due to the increase of viscosity of the solution that led to lowering of the diffusion coefficient of $\mathrm{HO}_{2}^{-}$.

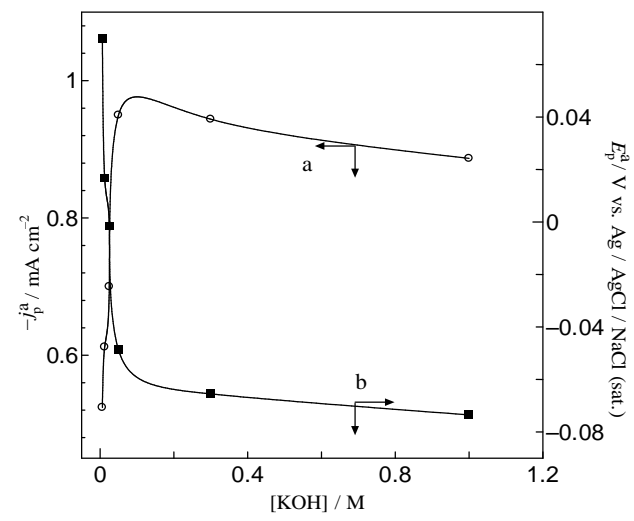

Fig. 5. Plots of (a) oxidation peak current and (b) peak potential vs. concentration of $\mathrm{OH}^{-}$. The Data were derived from the LSVs obtained at the $\mathrm{OH}^{-} \mid \mathrm{Au}$ (poly) electrode in $\mathrm{KOH}$ solution having its concentration in the range of $0.00625-1.0 \mathrm{M}$ in the presence of $1.0 \mathrm{HO}_{2}^{-}$.

Fig 5 (b) shows that the oxidation peak potential exponentially shifts to negative direction of potential when $[\mathrm{KOH}] \leq 0.1 \mathrm{M}$. For $[\mathrm{KOH}]>0.1 \mathrm{M}$ the peak potential shows a level off trend. Being inner sphere reaction, oxidation of $\mathrm{HO}_{2}{ }^{-}$takes place at the bare portion of the electrode. Thus an optimized value of $\Gamma_{\mathrm{OH}}{ }^{-}$is essentially important for the catalytic oxidation.

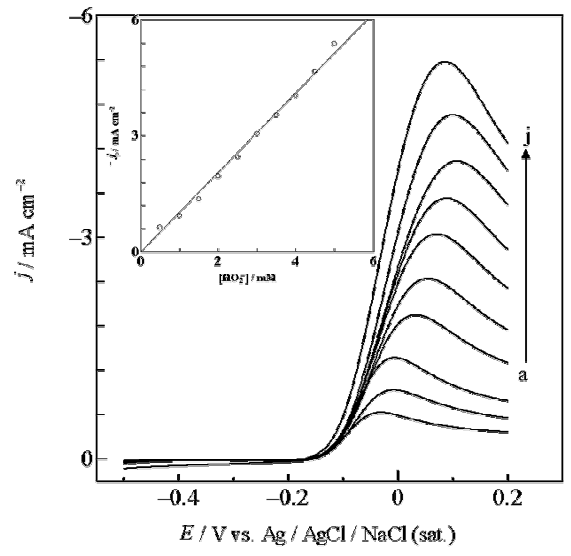

Fig. 6. LSVs obtained at the $\mathrm{OH}^{-} \mid \mathrm{Au}$ electrode in $0.1 \mathrm{M} \mathrm{KOH}$ solution in the presence of (a) 0.5 , (b) 1.0, (c) 1.5, (d) 2.0, (e) 2.5, (f) 3.0, (g) 3.5, (h) 4.0, (i) 4.5 and (j) $5.0 \mathrm{mM}$ $\mathrm{HO}_{2}^{-}$(form bottom to top). Inset shows the linear plot of peak current vs. concentration of $\mathrm{HO}_{2}^{-}$. 
Determination of a calibration curve: LSVs were obtained at the $\mathrm{OH}^{-} \mid \mathrm{Au}$ (poly) electrode in $\mathrm{N}_{2}$-saturated $0.1 \mathrm{M} \mathrm{KOH}$ solution containing $\mathrm{HO}_{2}^{-}$in the rage of 0.5 to 5.0 $\mathrm{mM}$ and the results are presented in Fig. 6. The oxidation peak currents were derived from the LSVs and plotted as a function of $\left[\mathrm{HO}_{2}^{-}\right]$and the result has been shown in the inset of Fig. 6. The values nicely $\left(R^{2}=0.997\right)$ fall on a straight line passing through the origin. The sensitivity of the electrode was obtained as $1.028 \mathrm{~A} \mathrm{~cm}^{-2} \mathrm{M}^{-1}$.

\section{CONCLUSIONS}

The in situ fabricated $\mathrm{OH}^{-} \mid \mathrm{Au}$ (poly) electrode showed an enhanced catalytic activity towards the oxidation of $\mathrm{HO}_{2}^{-}$. The peak current of oxidation of $\mathrm{HO}_{2}^{-}$significantly increased as compared with the bare clean $\mathrm{Au}$ (poly) electrode. The anodic response of $\mathrm{HO}_{2}{ }^{-}$oxidation was highly stable over a wide range of potential scan rates. The oxidation of $\mathrm{HO}_{2}^{-}$was a diffusion controlled process. The anodic transfer coefficient of $\mathrm{HO}_{2}{ }^{-}$ oxidation was estimated as 0.47 . Competitive adsorption of $\mathrm{Cl}^{-}$with $\mathrm{OH}^{-}$severely poisoned the catalytic activity of the $\mathrm{OH}^{-} \mid \mathrm{Au}$ (poly) electrode towards the oxidation of $\mathrm{HO}_{2}^{-}$. The optimum concentration of $\mathrm{KOH}$ for the maximum catalytic activity was obtained as ca. 0.1 M. A linear calibration curve was obtained in the concentration range of 0.5-5.0 mM of $\mathrm{HO}_{2}^{-}$with a sensitivity equal to $1.028 \mathrm{~A} \mathrm{~cm}^{-2} \mathrm{M}^{-1}$. Thus the in situ fabricated $\mathrm{OH}^{-} \mid \mathrm{Au}$ (poly) electrode can advantageously be used for the detection of $\mathrm{OH}_{2}{ }^{-}$ without the use of any additional reagent.

\section{ACKNOWLEDGEMENTS}

The work was financially supported by the grants from (i) Research Center of Shahjalal University of Science and Technology, Sylhet-3114 to Prof. Dr. Md. Rezwan Miah (Code number PS 06) and (ii) Ministry of Education, The People's Republic of Bangladesh to Prof. Mohammad Abul Hasnat and Prof. Dr. Md. Rezwan Miah, Department of Chemistry, Shahjalal University of Science and Technology, Sylhet-3114, Bangladesh.

\section{REFERENCES}

Badets, V., J. Pandard, N. Sojic and Stéphane A. 2016. Deciphering the platinized surface reactivity to improve the detection of hydrogen peroxide in bioanalyses. ChemElectroChem. 3: 22882296.

Laviron, E. 1979. General expression of the linear potential sweep voltammogram in the case of diffusionless electrochemical systems. J. Electroanal. Chem. 101: 19-28.

Lin, C.-H, L.-Y. Weia, J.-H. Leea, C.-L. Liena, C.-H. Lu, C.-J. Yuan. 2015. Effect of anions on the oxidation and reduction of hydrogen peroxide on the gold nanoparticle-deposited carbon fiber paper electrode. Electrochim. Acta. 180: 64-70.

Miah, Md.R. and T. Ohsaka. 2006. Enhanced electrochemical oxidation of $\mathrm{H}_{2} \mathrm{O}_{2}$ at iodine-modified gold electrode in alkaline media. J. Electrochem. Soc. 153(12): E195-E200. 
Miah, Md.R. and T. Ohsaka. 2009. Electrochemical oxidation hydrogen peroxide at a bromine adatom-modified gold electrode in alkaline media. Electrochim. Acta. 54: 1570-1577.

Miah, Md.R. and T. Ohsaka. 2006. Cathodic detection of $\mathrm{H}_{2} \mathrm{O}_{2}$ using iodide-modified gold electrode in alkaline media. Anal. Chem. 78: 1200-1205.

Miah, Md.R., D. Sen, R. Saha and M.A. Hasnat. 2016. Enhanced electrochemical oxidation of hydrogen peroxide at hydroxyl ion-modified gold electrode in alkaline media. J. Bangladesh Acad. Sci. 40(2): 125-135 and the references there in.

Miah, Md.R., T. Okajima and T. Ohsaka. 2016. Oxygen reduction reaction at in situ fabricated active gold over layers in acidic media. Int. J. Electrochem Sci. 11: 7909-7921.

Marichev, V.A. 1998. The adsorption of hydroxide ions on metals. Electrochim. Acta. 43: 22032214.

Nouri-Nigjeh, E., A.P. Bruins, R. Bischoff and H.P. Permentier. 2012. Electrocatalytic oxidation of hydrogen peroxide on a platinum electrode in the imitation of oxidative drug metabolism of lidocaine. Analyst. 137: 4698-4702.

Zhang, L., Z. Fang, Y. Ni and G. Zhao. 2009. Direct electrocatalytic oxidation of hydrogen peroxide based on nafion and microspheres $\mathrm{MnO}_{2}$ modified glassy carbon electrode. Int. J. Electrochem. Sci. 4: 407-413.

Zhang, L., F. Yuan, X. Zhang and L. Yang. 2011. Facile synthesis of flower like copper oxide and their application to hydrogen peroxide and nitrite sensing. Chem. Central J. 5(75): 1-9.

(Received revised manuscript on 26 April, 2017) 